\title{
CALL FOR PAPERS: CHILDREN'S CAPACITIES IN LEGAL CONTEXTS
}

Law and Human Behavior invites manuscript submissions for a special issue on children's capacities in legal contexts. In the area of children and the law, the issue of children's capacities may be the most salient and important intersection for collaboration between psychologists and legal scholars. During the past 10 to 15 years, several studies of adolescents' capacities to make informed decisions, e.g., in understanding their Miranda Rights and in medical treatment situations, have raised questions regarding more active participation in legal decision making. Mostly, these studies have been designed within the framework of informed consent; however, recently, scholars have suggested the need to examine components such as judgment, maturity, and risk analysis as well. In addition, children's memory and suggestibility have been raised as special concerns for both adolescents and younger children. Research content areas that warrant attention are children's capacity to commit a crime, to stand trial, to consent to treatment, to consent to research, to testify, and to express a preference in custody disputes. Thus, Law and Human Behavior is soliciting papers on any of these or related areas for a special issue entitled "Children's Capacities in Legal Contexts."

The editors for this issue are Law and Human Behavior Associate Editor N. Dickon Reppucci and Jennifer Woolard and Richard Redding of the University of Virginia. Manuscripts, in triplicate, should be sent to:

Professor N. Dickon Reppucci

Department of Psychology

Gilmer Hall

University of Virginia

Charlottesville, VA 22903

To be considered for this special issue, manuscripts must be postmarked no later than February 1, 1995. 